\title{
Treatment Patterns and Appropriateness of Antipsychotic Prescriptions in Patients with Schizophrenia
}

\section{Verónica Gamón}

Fundación para el Fomento de la Investigación Sanitaria y Biomédica de la Comunitat Valenciana Isabel Hurtado ( $\sim$ hurtado_isa@gva.es )

Fundación para el Fomento de la Investigación Sanitaria y Biomédica de la Comunitat Valenciana José Salazar-Fraile

Centro de Investigación Biomédica en Red de Salud Mental

\section{Gabriel Sanfélix-Gimeno}

Fundación para el Fomento de la Investigación Sanitaria y Biomédica de la Comunitat Valenciana

\section{Research Article}

Keywords: Schizophrenia, Antipsychotic Prescriptions, Treatment Patterns, Appropriateness, symptoms

Posted Date: February 5th, 2021

DOI: https://doi.org/10.21203/rs.3.rs-177191/v1

License: (c) (i) This work is licensed under a Creative Commons Attribution 4.0 International License. Read Full License 


\section{Abstract}

Schizophrenia is a chronic mental condition presenting a wide range of symptoms. Although this mental disorder has a low prevalence in comparison to other mental conditions, it has a negative impact on social and occupational functioning. This study is aimed to assess the inappropriateness of antipsychotic medication among schizophrenic patients and describe current patterns in the treatment of schizophrenia. A retrospective cohort study was conducted including all patients over the age of 15 with an active diagnosis of schizophrenia and treated with antipsychotics between 2008 and 2013 in the Valencia region. 19,718 patients with a diagnosis of schizophrenia and treated with antipsychotic medication were identified. The main outcome was inappropriateness of the pharmacotherapeutic management, including polypharmacy use: $30.4 \%$ of patients received antipsychotic polypharmacy (6.8\% were prescribed 3 or more antipsychotics); overdosage: a total of 318 individuals (1.6\%) exceeded the maximum daily doses; and use of concomitant psychotropics without an associated diagnosis: $21.5 \%$ of patients received psychotropic drugs concomitantly without associated psychiatric diagnoses. Overall, females and those who had a comorbid condition, such as anxiety or depression, were less likely to receive antipsychotic polypharmacy. In contrast, concomitant treatment with other psychoactive drugs, such as antiparkinson drugs, anxiolytics and hypnotics and more visits to mental health hospital increased the risk of polypharmacy use. In conclusion, a high level of inappropriateness has been detected among antipsychotic prescriptions. Practitioners should follow guidelines recommendations whenever possible in order to obtain the maximum benefit of antipsychotic medications without an increased risk of adverse effects in patients.

\section{Introduction}

Schizophrenia is a severe mental disorder affecting more than 21 million people worldwide. It is characterized by disordered thinking and behaviour, disorganized speech as well as perceptions, emotions and self-awareness disturbances [1,2]. Etiology of schizophrenia is still unknown, although it seems genetic, environmental and psychosocial factors contribute to the development of the disease [38]. Despite the prevalence of schizophrenia is lower compared to other psychosis (3.46 cases per year per 1000 inhabitants) [9], it is a considerable cause of disability at the personal, social and professional functioning, being among the top 15 disability-causing diseases in the world [10] and contributing to a decline in life expectancy [11-13]. Psychopharmacological treatment is aimed to reduce the frequency and severity of bouts, as well as to improve the functionality and quality of life of patients.

The recommendations proposed in Clinical Practice Guidelines (CPG) will be followed and adapted according to individual needs and characteristics of the patient, thus facilitating therapeutic compliance. According guidelines, the selection of antipsychotic medication will depend on the phase of schizophrenia or whether it is a relapse or a lack of response to treatment. In first episode psychosis the dosing regimen will be the minimum effective dose (MED), which will be adjusted individually according to response and tolerability. Nevertheless, maximum doses should never be exceeded due to increased risk of adverse effects. On the other hand, combination of more than one antipsychotic is generally not 
justified except when it is necessary to gradually switch from one antipsychotic to another or when it is added to an antipsychotic long-acting injectable (LAl) to stabilise the disease. Finally, use of benzodiazepines, antidepressants and mood stabilizers for the treatment of comorbid conditions is considered acceptable.

This study is conducted to generate information on the management of schizophrenic patients treated with antipsychotics by assessing the appropriateness of antipsychotic medication. Additionally, this study aims to describe other relevant aspects of the pharmacotherapeutic management patterns of schizophrenic patients and to identify factors associated with prevalence of antipsychotic polypharmacy.

\section{Methods}

\section{Study design}

A retrospective cohort study was conducted of all patients aged 15 and older with an active diagnosis of schizophrenia and treated with antipsychotics between 2008 and 2013 in the Spanish National Health System, specifically in the population of the Valencia region.

\section{Setting}

The study has been carried out for the population covered by the Valencia Health Agency (VHA), about $97 \%$ of the 5 million inhabitants of the Valencia region, which is located on the Mediterranean coast of Spain. Thanks to the linkage of the population-based databases, we have obtained a wide range of patient information regarding clinical and sociodemographic aspects. This has allowed us to obtain robust evidence on routine clinical practice (Real World Evidence-RWE), providing information which would be of great interest for healthcare management and clinical improvement, and immediately applicable to enhance the management of these patients.

\section{Population}

The study includes all patients diagnosed with schizophrenia (International Classification of Diseases, ninth revision, Clinical Modification, ICD-9-CM, codes 295.0-295.9) in the electronic medical records of VHA between January 1, 2008 and December 31, 2013.

The population was narrowed down to schizophrenic patients treated with antipsychotic drugs, which was defined as having at least one prescription/dispensing of an antipsychotic drug (ATC code N05A except N05AN) during the study period. The index date for the cohort was defined as the date of the first prescription/dispensing of one or more antipsychotics.

The exclusion criteria were patients with a first diagnosis of schizophrenia after the age of 65, people without pharmaceutical/health coverage by the Valencia Health System (VHS), mainly Spanish government employees whose prescriptions are reimbursed by civil servant insurance mutualities, and 
thus not included in the electronic records of the VHS, and people not registered in the municipal census, such as non-residents or temporary residents.

\section{Data sources}

The main data source was the Valencia health system integrated database (VID) [14] which is the electronic health information system provided by the Regional Valencian Ministry for Health linked individually through a unique patient identifier (UPI). The Population Information System (SIP) registers sociodemographic data as well as dates and causes of VHA withdrawal, including death. The Ambulatory Information System (SIA) provides with information on active diagnoses, personal and family history, laboratory test results, lifestyle factors, etc. and the pharmaceutical module (GAIA) provides with information on outpatient prescriptions and dispensations. The Minimum Basic Data Set at Hospital Discharge (MBDS) is a synopsis of clinical and administrative information of all hospital admissions, including diagnoses and procedures, and Accident \& Emergency Department (AED) clinical record collects visits to this department and associated diagnoses, as well as the date of discharge.

\section{Inappropriateness indicators}

The main outcome measure was the inappropriateness of the pharmacotherapeutic management in patients receiving an antipsychotic treatment for schizophrenia. For this purpose, several CPGs were checked in a first review [15-19] and we selected the most internationally well-known and/or those more recently published: National Institute for Health and Care Excellence (NICE) Clinical Guidance [20], British Association for Psychopharmacology (BAP) Schizophrenia Guidelines [21] and The American Psychiatric Association (APA) Practice Guideline for the Treatment of Patient with Schizophrenia [22]. Three indicators based on the recommendations of these CPGs and summaries of product characteristics (SmPC) were applied: 1) Concomitant use of more than one antipsychotic drug (polytherapy), defined as having more than one antipsychotic drug prescribed simultaneously within 30 days of the index date. 2) Patients exceeding the maximum daily dose (MDD) of an antipsychotic drug specified in the SmPC. 3) Patients treated simultaneously with other psychotropic drugs without having an associated psychiatric diagnosis.

Additionally, other relevant aspects related to the pharmacotherapeutic management patterns in patients with schizophrenia were assessed: type of antipsychotic drug prescribed (First-generation antipsychoticFGA vs Second-generation antipsychotic-SGA or a combination of both), patients treated with clozapine (clozapine monotherapy or clozapine combined with other antipsychotic drug), and individuals exceeding maximum recommended daily dose (MRDD). Moreover, the most frequently prescribed concomitant psychotropic drugs were identified.

\section{Covariates}

To describe the population we included demographic and clinical characteristics, and healthcare resource utilization in the preceding 12 months at the index date. Comorbidity was defined as the presence of an active diagnosis of the particular condition in the EMR within a 12-month period preceding the index date 
(Supplementary Table S1 shows details on definitions of comorbidities). The information during previous year was used to define use of concomitant medication and use of the health services. Prescriptions of other psychotropic drugs within 15 days before the index date and 15 days after were also identified (see Supplementary Table S2).

Covariates related to prescription or dispensing included name of the medicinal product, pharmaceutical form, drug dose, dosage regimen, route of administration (oral or long-acting injectable), prescription/dispensing date and RELE (electronic dispensing).

\section{Statistical analysis}

Socio-demographic and clinical characteristics of patients, as well as variables related to concomitant treatments and use of health system services, were described by means of descriptive analysis, using mean and standard deviation for continuous variables and percentages for categorical variables. The cohort of patients treated with antipsychotics was divided according to two criteria. Depending on whether or not patients had received antipsychotic treatment in the year prior to the index date, the cohort was stratified in prevalent and new users, respectively. Depending on the patient's age at the index date the cohort was divided in two groups: subjects under 40 years of age and subjects 41 years of age and older.

The appropriateness of pharmacotherapeutic management was assessed by describing some criteria used as adequacy proxies: polypharmacy with different antipsychotic drugs (categorized by overlap of two or more antipsychotics and 3 or more), exceeding the maximum daily doses specified in the SmPC and concomitant use of other psychotropic drugs and antipsychotics without an adequate psychiatric diagnosis.

In order to identify other relevant aspects of the management patterns of schizophrenic patients, other variables related to pharmacotherapeutic treatment were described: type of antipsychotic drug treatment, use of clozapine and exceeding maximum recommended doses of antipsychotic.

Factors (sociodemographic, clinical and other variables) associated with the prescription of 2 or more antipsychotics concomitantly were identified. For this purpose, stepwise logistic regression models were used and the corresponding Odds Ratios were estimated with their respective $95 \%$ confidence intervals $(95 \% \mathrm{Cl})$, with entry and exit significance levels of 0.05 and 0.1 respectively.Three models were conducted, one for all patients and one for each of the subgroups, new users and prevalent users, to determine which individual covariables were associated with polypharmacy use.

All statistical analyses were conducted using STATA 14R@ (StataCorp, College Station, TX).

\section{Ethics approval}

This is an observational, retrospective study without interventional or randomized trials, and therefore it does not entail an additional risk to patients nor can bring about prescription of any medication. The 
protocol for this study was approved by the Ethics Committee for Clinical Research of the General Directorate of Public Health and the Centre of Public Health Research (CEIC DGSP-CSISP, July 31, 2015). All methods were performed in accordance with the relevant guidelines and regulations. Patient informed consent exemption was approved by the aforementioned Committee given the nature of the study. All patient data were transferred to the research team anonymized and de-identified prior to analysis according to Spanish laws on privacy (Act 15/1999) and patient's rights (Act 41/2002).

\section{Results}

Patients with a diagnosis of schizophrenia and at least one antipsychotic drug prescription (or dispensing) were selected during the study period. Patients who met the exclusion criteria previously quoted were excluded from the study (Fig. 1).

A total of 19,718 subjects were included in the study ( $64.8 \%$ men) of whom $41.3 \%$ were new users (mean age $39.5, S D=12.1$ ) and $57.8 \%$ were prevalent users (mean age $41.6, S D=12.1$ ) of antipsychotic medications. $52.2 \%$ were aged between 16 and 40 years and $47.8 \%$ were aged 41 years or more. Patient characteristics are described in Table 1. 
Table 1

Patient characteristics

\begin{tabular}{|c|c|c|c|c|c|c|}
\hline \multirow[t]{3}{*}{ 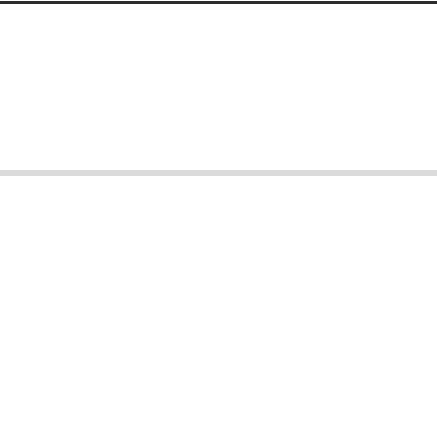 } & \multicolumn{3}{|c|}{$\begin{array}{l}\text { New users } \\
n=8,141 \text { (41.3\%) }\end{array}$} & \multicolumn{3}{|c|}{$\begin{array}{l}\text { Prevalent users } \\
n=11,577(58.7 \%)\end{array}$} \\
\hline & $\begin{array}{l}\text { 16- } \\
\text { 40years }\end{array}$ & $\begin{array}{l}\geq 41 \\
\text { years }\end{array}$ & \multirow{2}{*}{$\begin{array}{l}\text { Total } \\
8,141 \\
(41.9)\end{array}$} & $\begin{array}{l}16- \\
40 y e a r s\end{array}$ & $\begin{array}{l}\geq 41 \\
\text { years }\end{array}$ & \multirow{2}{*}{$\begin{array}{l}\text { Total } \\
11,577 \\
(58.7)\end{array}$} \\
\hline & $\begin{array}{l}4,522 \\
(55.6)\end{array}$ & $\begin{array}{l}3,619 \\
(45.5)\end{array}$ & & $\begin{array}{l}5,770 \\
(49.8)\end{array}$ & $\begin{array}{l}5,807 \\
(50.2)\end{array}$ & \\
\hline Female & $\begin{array}{l}1,331 \\
(29.4)\end{array}$ & $\begin{array}{l}1,517 \\
(41.9)\end{array}$ & $\begin{array}{l}2,848 \\
(35.0)\end{array}$ & $\begin{array}{l}1,683 \\
(29.2)\end{array}$ & $\begin{array}{l}2,405 \\
(41.4)\end{array}$ & $\begin{array}{l}4,088 \\
(35.3)\end{array}$ \\
\hline \multicolumn{7}{|c|}{ Psychiatric comorbidities } \\
\hline Depression & $\begin{array}{l}652 \\
(14.4)\end{array}$ & $\begin{array}{l}628 \\
(17.4)\end{array}$ & $\begin{array}{l}1,280 \\
(15.7)\end{array}$ & $\begin{array}{l}643 \\
(11.1)\end{array}$ & $\begin{array}{l}718 \\
(12.4)\end{array}$ & $\begin{array}{l}1,361 \\
(11.4)\end{array}$ \\
\hline Dementia & $22(0.5)$ & $60(1.7)$ & $82(1.0)$ & $82(1.4)$ & $112(1.9)$ & $194(1.7)$ \\
\hline Epilepsy & $87(1.9)$ & $84(2.3)$ & $\begin{array}{l}171 \\
(2.1)\end{array}$ & $133(2.3)$ & $116(2.0)$ & $249(2.2)$ \\
\hline Parkinson's disease & $4(0.1)$ & $28(0.8)$ & $32(0.4)$ & $8(0.1)$ & $35(0.6)$ & $43(0.4)$ \\
\hline Anxiety & $\begin{array}{l}1,310 \\
(29.0)\end{array}$ & $\begin{array}{l}869 \\
(24.0)\end{array}$ & $\begin{array}{l}2,179 \\
(26.8)\end{array}$ & $\begin{array}{l}1,257 \\
(21.8)\end{array}$ & $\begin{array}{l}1,101 \\
(19.0)\end{array}$ & $\begin{array}{l}2,358 \\
(20.4)\end{array}$ \\
\hline Alcohol abuse & $\begin{array}{l}284 \\
(6.3)\end{array}$ & $\begin{array}{l}259 \\
(7.2)\end{array}$ & $\begin{array}{l}543 \\
(6.7)\end{array}$ & $261(4.5)$ & $228(3.9)$ & $489(4.2)$ \\
\hline Drug abuse & $\begin{array}{l}796 \\
(17.6)\end{array}$ & $\begin{array}{l}216 \\
(6.0)\end{array}$ & $\begin{array}{l}1,012 \\
(12.4)\end{array}$ & $\begin{array}{l}629 \\
(10.9)\end{array}$ & $145(2.5)$ & $774(6.7)$ \\
\hline Personality disorder & $\begin{array}{l}372 \\
(8.2)\end{array}$ & $\begin{array}{l}200 \\
(5.5)\end{array}$ & $\begin{array}{l}573 \\
(7.0)\end{array}$ & $352(6.1)$ & $168(2.9)$ & $520(4.5)$ \\
\hline Sleep disorder & $\begin{array}{l}250 \\
(5.5)\end{array}$ & $\begin{array}{l}291 \\
(8.0)\end{array}$ & $\begin{array}{l}541 \\
(6.7)\end{array}$ & $198(3.4)$ & $306(5.3)$ & $504(4.4)$ \\
\hline Delirium & $82(1.8)$ & $52(1.4)$ & $\begin{array}{l}134 \\
(1.7)\end{array}$ & $75(1.3)$ & $59(1.0)$ & $134(1.2)$ \\
\hline Other disorders ${ }^{a}$ & $\begin{array}{l}1,234 \\
(27.3)\end{array}$ & $\begin{array}{l}645 \\
(17.8)\end{array}$ & $\begin{array}{l}1,879 \\
(23.1)\end{array}$ & $\begin{array}{l}962 \\
(16.7)\end{array}$ & $\begin{array}{l}671 \\
(11.6)\end{array}$ & $\begin{array}{l}1,633 \\
(14.1)\end{array}$ \\
\hline \multicolumn{7}{|c|}{ Concomitant psychotropic drugs } \\
\hline Antidepressants & $\begin{array}{l}781 \\
(17.3)\end{array}$ & $\begin{array}{l}765 \\
(21.1)\end{array}$ & $\begin{array}{l}1,546 \\
(19.0)\end{array}$ & $\begin{array}{l}1,690 \\
(29.3)\end{array}$ & $\begin{array}{l}1,598 \\
(27.5)\end{array}$ & $\begin{array}{l}3,288 \\
(28.4)\end{array}$ \\
\hline Hypnotics/sedatives & $\begin{array}{l}484 \\
(10.7)\end{array}$ & $\begin{array}{l}487 \\
(13.5)\end{array}$ & $\begin{array}{l}971 \\
(11.9)\end{array}$ & $547(9.5)$ & $\begin{array}{l}773 \\
(13.3)\end{array}$ & $\begin{array}{l}1,320 \\
(11.4)\end{array}$ \\
\hline
\end{tabular}

aOther include: other organic psychosis, bipolar disorder, sexual disorder and acute stress reaction. 


\begin{tabular}{|c|c|c|c|c|c|c|}
\hline \multirow[b]{2}{*}{ Antidementia drugs } & \multicolumn{3}{|c|}{$\begin{array}{l}\text { New users } \\
n=8,141(41.3 \%)\end{array}$} & \multicolumn{3}{|c|}{$\begin{array}{l}\text { Prevalent users } \\
n=11,577 \text { (58.7\%) }\end{array}$} \\
\hline & $2(0.0)$ & $39(1.1)$ & $41(0.5)$ & $13(0.2)$ & $41(0.7)$ & $54(0.5)$ \\
\hline Anxiolytics & $\begin{array}{l}1,189 \\
(26.3)\end{array}$ & $\begin{array}{l}1,165 \\
(32.2)\end{array}$ & $\begin{array}{l}2,354 \\
(28.9)\end{array}$ & $\begin{array}{l}2,528 \\
(43.8)\end{array}$ & $\begin{array}{l}2,647 \\
(45.6)\end{array}$ & $\begin{array}{l}5,175 \\
(44.7)\end{array}$ \\
\hline Anticonvulsants & $\begin{array}{l}518 \\
(11.5)\end{array}$ & $\begin{array}{l}434 \\
(12.0)\end{array}$ & $\begin{array}{l}952 \\
(11.7)\end{array}$ & $\begin{array}{l}1,566 \\
(27.1)\end{array}$ & $\begin{array}{l}1,247 \\
(21.5)\end{array}$ & $\begin{array}{l}2,813 \\
(24.3)\end{array}$ \\
\hline Lithium & $64(1.4)$ & $73(2.0)$ & $\begin{array}{l}137 \\
(1.7)\end{array}$ & $248(4.3)$ & $281(4.8)$ & $529(4.6)$ \\
\hline Antiparkinson drugs & $\begin{array}{l}140 \\
(3.1)\end{array}$ & $\begin{array}{l}167 \\
(4.6)\end{array}$ & $\begin{array}{l}307 \\
(3.8)\end{array}$ & $\begin{array}{l}1,423 \\
(24.7)\end{array}$ & $\begin{array}{l}1,599 \\
(27.5)\end{array}$ & $\begin{array}{l}3,022 \\
(26.1)\end{array}$ \\
\hline \multicolumn{7}{|l|}{ Use of health services } \\
\hline Hospitalisations & $\begin{array}{l}1,200 \\
(26.5)\end{array}$ & $\begin{array}{l}848 \\
(23.4)\end{array}$ & $\begin{array}{l}2,048 \\
(25.2)\end{array}$ & $\begin{array}{l}979 \\
(17.0)\end{array}$ & $\begin{array}{l}748 \\
(12.9)\end{array}$ & $\begin{array}{l}1,727 \\
(14.9)\end{array}$ \\
\hline Mental health hospital & $\begin{array}{l}992 \\
(21.9)\end{array}$ & $\begin{array}{l}552 \\
(15.2)\end{array}$ & $\begin{array}{l}1,544 \\
(18.9)\end{array}$ & $\begin{array}{l}723 \\
(12.5)\end{array}$ & $415(7.1)$ & $\begin{array}{l}1,138 \\
(9.8)\end{array}$ \\
\hline No mental health hospital & $\begin{array}{l}280 \\
(6.2)\end{array}$ & $\begin{array}{l}344 \\
(9.5)\end{array}$ & $\begin{array}{l}624 \\
(7.7)\end{array}$ & $317(5.5)$ & $384(5.9)$ & $701(6.1$ \\
\hline $\begin{array}{l}\text { Mental health outpatient } \\
\text { clinic }\end{array}$ & $\begin{array}{l}2,549 \\
(56.4)\end{array}$ & $\begin{array}{l}1,920 \\
(53.1)\end{array}$ & $\begin{array}{l}4,469 \\
(54.9)\end{array}$ & $\begin{array}{l}5,109 \\
(88.5)\end{array}$ & $\begin{array}{l}5,018 \\
(86.4)\end{array}$ & $\begin{array}{l}10,127 \\
(87.5)\end{array}$ \\
\hline $\begin{array}{l}\text { No mental health } \\
\text { outpatient cinic }\end{array}$ & $\begin{array}{l}3,233 \\
(71.5)\end{array}$ & $\begin{array}{l}2,403 \\
(66.4)\end{array}$ & $\begin{array}{l}5,636 \\
(69.2)\end{array}$ & $\begin{array}{l}4,576 \\
(79.3)\end{array}$ & $\begin{array}{l}4,654 \\
(80.1)\end{array}$ & $\begin{array}{l}9,230 \\
(79.7)\end{array}$ \\
\hline A\&E & $\begin{array}{l}1,832 \\
(40.5)\end{array}$ & $\begin{array}{l}1,131 \\
(31.2)\end{array}$ & $\begin{array}{l}2,963 \\
(36.4)\end{array}$ & $2985.2)$ & $228(3.9)$ & $526(4.6)$ \\
\hline
\end{tabular}

Regarding inappropriateness of schizophrenia treatment (Table 2) the prevalence of antipsychotic polypharmacy (those treated with 2 or more antipsychotics) was $26.4 \%$ among new users and $33.3 \%$ of prevalent users. If we consider polypharmacy as being treated with 3 or more antipsychotic drugs, $5.5 \%$ of new users and $7.7 \%$ of prevalent users were treated with 3 or more antipsychotics. As for antipsychotic dosage, 107 new users (1.3\%) exceeded the maximum licensed daily doses, while 211 subjects (1.8\%) in maintenance therapy exceeded the maximum doses. A total of 9,479 subjects received concomitant treatment with psychotropic drugs, approximately half of which did not have an associated psychiatric diagnosis ( $17.2 \%$ of new users and $24.5 \%$ of prevalent users). 
Table 2

Inappropriateness of schizophrenia treatment

\begin{tabular}{|c|c|c|c|c|c|c|}
\hline & \multicolumn{3}{|c|}{$\begin{array}{l}\text { New users } \\
n=8,141(41.3 \%)\end{array}$} & \multicolumn{3}{|c|}{$\begin{array}{l}\text { Prevalent users } \\
n=11,577 \text { (58.7\%) }\end{array}$} \\
\hline & $\begin{array}{l}16-40 \\
\text { years }\end{array}$ & $\begin{array}{l}>=41 \\
\text { years }\end{array}$ & Total & $\begin{array}{l}16-40 \\
\text { years }\end{array}$ & $\begin{array}{l}>=41 \\
\text { years }\end{array}$ & Total \\
\hline \multicolumn{7}{|l|}{ Polytherapy } \\
\hline$\geq 2 \mathrm{AP}$ & $\begin{array}{l}1,230 \\
(27.2)\end{array}$ & $\begin{array}{l}918 \\
(25,4)\end{array}$ & $\begin{array}{l}2,148 \\
(26.4)\end{array}$ & $\begin{array}{l}1,956 \\
(33.9)\end{array}$ & $\begin{array}{l}1,899 \\
(32.7)\end{array}$ & $\begin{array}{l}3,855 \\
(33.3)\end{array}$ \\
\hline$\geq 3 \mathrm{AP}$ & $256(5.7)$ & $193(5.3)$ & $449(5.5)$ & $451(7.8)$ & $441(7.6)$ & $\begin{array}{l}1,341 \\
(6.8)\end{array}$ \\
\hline \multicolumn{7}{|l|}{ AP dosage } \\
\hline Exceeding MDD & $58(1.3)$ & $49(1.3)$ & $107(1.3)$ & $87(1.5)$ & $124(2.1)$ & $211(1.8)$ \\
\hline \multicolumn{7}{|c|}{ Concomitant psychotropic drugs } \\
\hline $\begin{array}{l}\text { Without psychiatric } \\
d x\end{array}$ & $672(14.8)$ & $\begin{array}{l}729 \\
(20.1)\end{array}$ & $\begin{array}{l}1,401 \\
(17.2)\end{array}$ & $\begin{array}{l}1,315 \\
(22.8)\end{array}$ & $\begin{array}{l}1,526 \\
(26.3)\end{array}$ & $\begin{array}{l}2,841 \\
(24.5)\end{array}$ \\
\hline
\end{tabular}

Patterns of pharmacotherapeutic management in schizophrenic patients are shown in Table 3. The vast majority of patients in monotheraphy group were treated with a SGA. Subjects treated with two or more APs, both new users and prevalent users, received almost entirely antipsychotic combinations that included at least a SGA (combination of SGA + FGA or 2 or more SGA). Only $4.5 \%$ of new users and $8.5 \%$ of prevalent users received combinations of 2 or more FGA. Regarding the use of clozapine, $189 \mathrm{new}$ users $(2.3 \%)$ were prescribed clozapine and of these, one third had it associated with another antipsychotic treatment. About half of prevalent users were prescribed clozapine in monotherapy and the other half were prescribed clozapine associated with another antipsychotic. As for recommended daily doses, 194 new users $(2.4 \%)$ and 371 prevalent users (3.2\%) received doses of antipsychotic above the recommended maximum range. 
Table 3

Patterns of management in schizophrenic patients

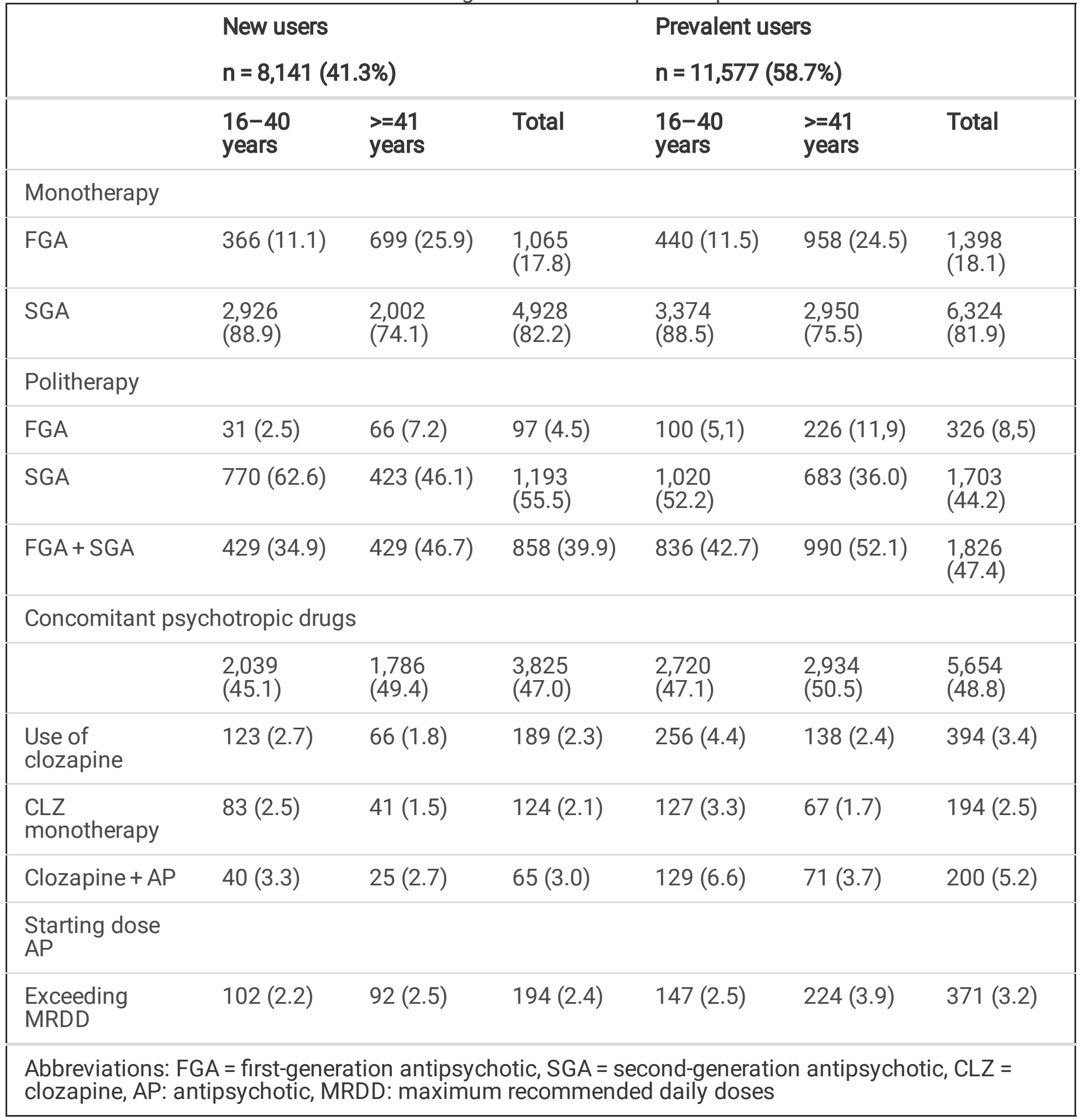

The prescription rate of combined antipsychotic with psychotropic drugs was similar between new users and prevalent users or even between age groups (Supplementary Table S3). In patients who were given combined polypharmacy with other psychotropic drugs, the association most commonly prescribed was 2 antipsychotics and one psychotropic drug. A negligible percentage of subjects received the association 
of 3 antipsycotics and one psychotropic drug. Moreover, the vast majority of hypnotics and about $70 \%$ of antidepressants and anxiolytics were prescribed without any previous diagnosis of the related disorder (Supplementary Table S4).

Factors associated with the prevalence of antipsychotic polypharmacy are shown in Fig. 2. For both groups, women and those being diagnosed with other psychiatric conditions, such as anxiety and depression, were less likely to receive polypharmacy. The use of psychotropic drugs concomitantly, such as antiparkinsonians, anxiolytics, hypnotics and lithium (the last one only in prevalent users) and visits to mental health hospital were related to a higher risk of being treated with more than one antipsychotic drug ( 1.5 to 2 times greater odds).

In new users, drug abuse, the presence of other mental disorders and emergency visits increased by about $20 \%$ the risk of antipsychotic polypharmacy. In contrast, hospitalisations for any reason and visits to outpatient clinic and mental health outpatient clinic decreased the likelihood of antipsychotic polypharmacy. In prevalent users, alcohol abuse and delirium have been associated with decreased risk of antipsychotic polypharmacy ( 1.3 and 1.5 times greater odds, respectively) and visits to mental health outpatient clinic have been associated with increased risk of antipsychotic polypharmacy (contrary to new users).

\section{Discussion}

This retrospective study provides information on the inappropriateness of antipsychotic treatment and management patterns in a large population cohort of patients with schizophrenia in a Mediterranean region of Europe, showing a high level of inappropriateness among antipsychotic prescriptions considering that between a quarter and a third of the schizophrenic patients were treated with more than one antipsychotic drug.

A tiny but relevant percentage of patients exceeded MDD of antipsychotic specified in SmPC. Approximately 1 out of 5 subjects treated with concomitant psychotropic drugs did not have an associated psychiatric diagnosis. Other relevant aspects of antipsychotic treatment patterns were the high percentage of treatment with SGAs, both in monotherapy and in polytherapy and the underuse of clozapine. In addition, the most common combination was 2 antipsychotics with one psychotropic drug, and the majority of antidepressants, anxiolytics and hypnotics were prescribed without an associated diagnosis. Finally, factors associated with increased polypharmacy use were concomitant treatment with other psychotropic drugs as anxiolytics and hypnotics and visits to mental health hospital. On the contrary, women and those who were diagnosed of anxiety or depression were less likely to receive antipsychotic polypharmacy. These results were similar to those reported by other studies [23, 24], reporting a polypharmacy rate of $30.4 \%$. Among new users, 1 out of 4 subjects were prescribed more than one antipsychotic and $5.5 \%$ were prescribed 3 or more antipsychotics. This high rate of inappropriateness is particularly relevant, considering that there is no strong evidence for the association of polypharmacy with a higher response [25]. However, most studies assert that the antipsychotic polypharmacy is linked 
to increased adverse effects, poor medication adherence and increased risk of drug interactions [26-28]. Prevalence of polypharmacy was higher in prevalent users: 1 out of 3 subjects were prescribed 2 or more antipsychotic drugs and $7.7 \%$ were prescribed 3 or more antipsychotic drugs. These data coincide with several studies showing that the longer the progression of schizophrenia the more common the antipsychotic polypharmacy [29,30], but as we have previously mentioned, antipsychotic combination should be avoided, except for short periods such as when switching antipsychotic medication. Althouth current treatment guidelines recommend antipsychotic monotherapy and assert that polypharmacy should be avoided in most cases, recent evidence shows that polypharmacy may be superior to monotherpy in certain clinical cases or for maintenance treatment [24, 31, 32]. This recent evidence, may suggest that treatment guidelines should update their recommendations considering this results.

Regarding antipsychotic dosage, although most prescriptions met guidelines recommendations, a sizeable percentage of subjects exceeded the maximum dose of antipsychotic (1.6\%). In all, a total of 107 new users and 211 prevalent users received dosages above maximum daily dose licensed in the SmPC. It is important to note that overdose of antipsychotics increases the risk of toxicity, especially in polypharmacy, although subsequent studies would be needed to estimate the clinical impact of inadequacy on the cohort studied [33-35]. In addition, almost $3 \%$ of subjects in both patient groups received antipsychotic doses above the higher end of the recommended range. According to various studies, patients with schizophrenia who do not respond to treatment are prescribed high dose therapy [36]. However, there is no evidence supporting this strategy and 2 of the 3 CPGs reviewed in this study recommend starting antipsychotic treatment with the lowest effective dose and gradually move to higher doses based on the patient's response. By contrast, antipsychotic doses above higher dose thresholds are associated with higher rates of adverse effects, a deterioration of cognitive function and an increased risk of mortality $[27,28,37,38]$.

As expected, the most frequent comorbidities were anxiety and depression [39]. Nearly half of the subjects received concomitant treatment with psychotropic drugs. Antidepressants were the most commonly prescribed psychotropic drugs, followed by anxiolytics. Although benzodiazepines are recommended by CPGs for the treatment of anxiety and insomnia, especially in the acute phase of schizophrenia [40], an overwhelming majority of subjects receiving a hypnotic treatment did not have a diagnosis of sleep disorder and a third of those who were prescribed an anxiolytic drug did not have a diagnosis of anxiety. As for depression, a common disorder in schizophrenia [41], 70\% of subjects treated with antidepressants did not have an associated diagnosis of depression. Although the use of these psychoactive drugs is accepted for comorbidities that are extremely prevalent in mental disorders, its use is not justified without having a previous diagnosis. A noteworthy result was that anticonvulsant use was more than twice in prevalent users than in new users. Concerning antiparkinson drugs, frequency of prescription in prevalent users (23.1\%) was remarkably higher than in new users (3.8\%). This substantial difference would stem from the use of antiparkinson medications to reduce antipsychotic extrapyramidal side effects [42]. 
With regard to the choice of antipsychotic medication, our results were in line with guidelines recommendations and therefore it was based not so much on efficacy, but on tolerance. In more than $80 \%$ of subjects with antipsychotic monotherapy, SGA was the first line drug. This decision could have possibly been related to a lower incidence of side effects and a rapid onset of efficacy $[43,44]$. In the same way as any other findings FGA were more commonly prescribed in older patients [45]: 1 out of 4 patients aged 41 years and 1 out of 10 patients under 40 years of age were prescribed FGA monotherapy. In patients with antipsychotic polypharmacy, the most frequent combination included SGA: FGA + SGA $(44.7 \%)$ and SGA + SGA (48.2\%). On the contrary, the association of two FGA was not very common (4.5\% in new users and $8.5 \%$ in prevalent users). Similarly to monotherapy group, combinations including at least one FGA in patients over 40 years of age were more frequent.

Nearly $3 \%$ of subjects were given clozapine, data very similar to those obtained in other studies [46]. According to several studies, $30 \%$ of patients diagnosed with schizophrenia are resistant to treatment, in which case clozapine should be introduced $[47,48]$. Our study confirms the underuse of clozapine in treatment-resistant schizophrenia (TRS) [49], being more common antipsychotic augmentation and higher doses of antipsychotic [50]. Overall, the prevalence of clozapine use was significantly higher in young patients (15-40 years) and in prevalent users. The most striking result was as for new users: 123 subjects aged between 16-40 years and 66 subjects aged 41 years or older were given clozapine in a first episode of schizophrenia, 124 of them as monotherapy and 65 combined with another antipsychotic. Although the percentage is low (2.3\%), all the revised CPGs agrees on clozapine use should be restricted just to patients with a clinically inadequate response after at least two trials with different antipsychotics, at an adequate dosage and duration [51].

\section{Limitations}

Reporting bias may exist due to the absence of data record or differences in data logging practices in electronic medical history, however, this problem should always be taken into account when using data from routine clinical practice. Second, although currently prescriptions in the VHA are mostly electronic, there are still $1 \%$ of manual prescriptions. The study included data since 2008 , when this percentage was slightly higher, although still small (about $5 \%$ ). In addition, in some electronic prescriptions the antipsychotic starting dose might have been handwritten, being the maintenance dose the only one registered in electronic health records. Third, overlap in prescribing 2 or more antipsychotics could exist when switching of antipsychotic medication or formulation. In this case we considered polytherapy even though the patient was not taking both drugs simultaneously.

Fourth, due to the descriptive nature of the study, our results may not be extrapolated to other populations, representing the current therapeutic patterns of this population. Nevertheless, these results provide a broad in-depth overview of the pharmacotherapeutic management in routine clinical practice for a very large representative population of a complete region of Spain. Fifth, we have used CPGs from America, Canada and the United Kingdom for application in population of the Valencia region, with different characteristics to the population of the areas where the guidelines have been developed. Finally, 
in patients with a disease progression (prevalent users) and who were treated with clozapine, it is difficult to know whether recommendations have been followed before prescribing this antipsychotic drug reserved for treatment-resistant schizophrenia. That is why we have not considered the use of clozapine as a main criterion of inappropriateness.

\section{Implications and future considerations}

In summary, this study shows that despite the recommendations provided by CPGs, antipsychotic polytherapy is still widespread among patients with schizophrenia. This, coupled with antipsychotic antipsychotic combinations with other psycotropic drugs, is expected to hinder therapeutic compliance due to increased side effects and drug interactions and, as a consequence, to an inadequate management of the schizophrenic patient. Otherwise, it would appear to have a negative impact on social integration and workforce reintegration. However, further studies would be needed to estimate the clinical impact arisen from inappropriateness of antipsychotic treatment.

On the other hand, this study aims to highlight the importance of a responsible prescription and a rational use of antipsychotics by mental health practitioners. In addition, we consider of great importance to address this type of disorders through a multidisciplinary team, achieving a balance between pharmacological and psychological therapy.

\section{Declarations}

\section{AUTHOR CONTRIBUTIONS}

VG, IH and GS were responsible for the study concept, design and data acquisition. IH carried out the data preparation and the statistical analysis, VG drafted the manuscript and GS prepared figures 1 and 2. VG, $\mathrm{IH}$ and GS participated in the analysis and interpretation of data. JS conducted the critical revision of the manuscript for important intellectual content. All authors approved the final version submitted for publication and agree to be accountable for all aspects of the work in ensuring that questions related to the accuracy or integrity of any part of the work are appropriately investigated and resolved.

\section{Funding}

This study was funded by Instituto de Salud Carlos III. Grant number: PI17/02259

\section{Conflicts of interest}

Verónica Gamón, Isabel Hurtado, Gabriel Sanfélix-Gimeno and José Salazar-Fraile declare that they have no conflict of interest.

\section{References}


1. World Health Organization (WHO). Schizophrenia. https://www.who.int/news-room/factsheets/detail/schizophrenia (2019).

2. Kahn, R. et al. Schizophrenia. Nature Review Disease Primers. 1, 15067 (2015).

3. Hoffmann, A., Ziller, M. \& Spengler, D. Focus on Causality in ESC/iPSC-Based Modeling of Psychiatric Disorders. Cells. 9, 366 (2020).

4. Fatima, W., Riaz, S., Aiman Shahzad, M., Naz, Z., Mahmood, S. \& Hasnain, S. Chromosomal region $1 \mathrm{q} 24.1$ is associated with increased risk of schizophrenia in Pakistani population. Gene. 734, 144390 (2020).

5. Tandon, R., Keshavan, M. S. \& Nasrallah, H. A. Schizophrenia, "just the facts" what we know in 2008. 2. Epidemiology and etiology. Schizophr Res. 102, 1-18 (2008).

6. Vassos, E., Pedersen, C.B., Murray, R. M., Collier, D. A. \& Lewis, C. M. Meta-analysis of the association of urbanicity with schizophrenia. Schizophr Bull. 38, 1118-1123 (2012).

7. Costa, E., Silva, J. A. \& Steffen, R. E. Urban environment and psychiatric disorders: a review of the neuroscience and biology. Metabolism. 100S, 153940 (2019).

8. Reinhard, M. A. et al. The vicious circle of social exclusion and psychopathology: a systematic review of experimental ostracism research in psychiatric disorders. Eur Arch Psychiatry Clin Neurosci. 270, 521-532 (2019)

9. Moreno-Küstner, B. et al. Prevalence of schizophrenia and related disorders in Malaga (Spain): results using multiple clinical databases. Epidemiol Psychiatr Sci. 25, 38-48 (2016).

10. Global Burden of Disease Study 2013 Collaborators. Global, regional, and national incidence, prevalence, and years lived with disability for 301 acute and chronic diseases and injuries in 188 countries, 1990-2013: a systematic analysis for the Global Burden of Disease Study 2013. Lancet. 386, 743-800 (2015).

11. Brown, S., Kim, M., Mitchell, C. \& Inskip, H. Twenty-five year mortality of a community cohort with schizophrenia. Br J Psychiatry. 196, 116-121 (2010).

12. Seeman, M.V. Schizophrenia Mortality: Barriers to Progress. Psychiatr Q. 90, 553-563 (2019).

13. Gerlinger, G., Hauser, M., De Hert, M., Lacluyse, K., Wampers, M. \& Correll, C.U. Personal stigma in schizophrenia spectrum disorders: a systematic review of prevalence rates, correlates, impact and interventions. World Psychiatry. 12, 155-164 (2013).

14. García-Sempere, A. et al. Data resource profile: the Valencia health system integrated database (VID). Int J Epidemiol. 49, 740-741 (2020).

15. Servicio Andaluz de Salud. Guía Práctica para el Tratamiento de la Psicosis y Esquizofrenia. Manejo en Atención Primaria y en Salud Mental. Consejería de Salud y Familias. Junta de Andalucía; (2019)

16. Remington, G., Addington, D., Honer, W., Ismail, Z., Raedler, T. \& Teehan M. Guidelines for the Pharmacotherapy of Schizophrenia in Adults. Can J Psychiatry. 62, 604-616 (2017).

17. Grupo de trabajo de la Guía de Práctica Clínica sobre la Esquizofrenia y el Trastorno Psicótico Incipiente. Fòrum de Salut Mental, coordinación. Guía de Práctica Clínica sobre la Esquizofrenia y el 
Trastorno Psicótico Incipiente. Madrid: Plan de Calidad para el Sistema Nacional de Salud del Ministerio de Sanidad y Consumo. Agència d'Avaluació de Tecnologia i Recerca Mèdiques; Guía de Práctica Clínica: AATRM. Nº 2006/05-2 (2009).

18. Subdirección de Salud Mental, Servicio Murciano de Salud. Guía Práctica Clínica para el Tratamiento de la Esquizofrenia en Centros de Salud Mental; (2009).

19. Kreyenbuhl, J., Buchanan, R. W., Dickerson, F. B. \& Dixon, L. B. Schizophrenia Patient Outcomes Research Team (PORT). The Schizophrenia Patient Outcomes Research Team (PORT): updated treatment recommendations 2009. Schizophr Bull. 36, 94-103 (2009).

20. NICE, National Institute for Health and Clinical Excellence. Psycosis and Schizophrenia in adults. The NICE Guideline on treatment and management, (2014).

21. Barnes, T. R. et al. Evidence-based guidelines for the pharmacological treatment of schizophrenia: Updated recommendations from the British Association for Psychopharmacology. $J$ Psychopharmacol. 34, 3-78 (2020).

22. The American Psychiatric Association practice guideline for the treatment of patients with schizophrenia. (2019).

23. Bernardo, M., Coma, A., Ibáñez, C., Zara, C., Bari, J. M. \& Serrano-Blanco, A. Antipsychotic polypharmacy in a regional health service: a population-based study. BMC Psychiatry. 12, 42 (2012).

24. Moore, B. A., Morrissette, D. A., Meyer, J. M. \& Stahl, S. M. Drug information update. Unconventional treatment strategies for schizophrenia: polypharmacy and heroic dosing. BJPsych Bull. 41, 164-168 (2017).

25. Galling, B. et al. Antipsychotic augmentation vs. monotherapy in schizophrenia: systematic review, meta-analysis and meta-regression analysis. World Psychiatry. 16, 77-89 (2017).

26. Baandrup, L. Polypharmacy in schizophrenia. Basic Clin Pharmacol Toxicol. 126, 183-192 (2020).

27. Pae, C. U. Antipsychotic Polypharmacy in Treatment of Schizophrenia; Should or Should Not? Chonnam Med J. 56, 157-165 (2020).

28. Jeon, S. W. \& Kim, Y.K. Unresolved Issues for Utilization of Atypical Antipsychotics in Schizophrenia: Antipsychotic Polypharmacy and Metabolic Syndrome. Int J Mol Sci. 18, 2174 (2017).

29. Suokas, J. T., Suvisaari, J. M., Haukka, J., Korhonen, P. \& Tiihonen, J. Description of long-term polypharmacy among schizophrenia outpatients. Soc Psychiatry Psychiatr Epidemiol. 48, 631-638 (2013).

30. Nguyen, M. L., Sunderland, B., Lim, S., Hattingh, L. \& Chalmers, L. The hidden magnitude of polypharmacy: using defined daily doses and maximum licensed daily doses to measure antipsychotic load. Int J Clin Pharm. 41, 1642-1651 (2019).

31. Tiihonen, J., Taipale, H., Mehtälä, J., Vattulainen, P., Correll, C.U. \& Tanskanen, A. Association of Antipsychotic Polypharmacy vs Monotherapy With Psychiatric Rehospitalization Among Adults With Schizophrenia. JAMA Psychiatry. 76, 499-507 (2019). 
32. Correll, C. U., Rummel-Kluge, C., Corves, C., Kane, J. M. \& Leucht, S. Antipsychotic combinations vs monotherapy in schizophrenia: a meta-analysis of randomized controlled trials. Schizophr Bull. 35, 443-57 (2009).

33. Minns, A. B. \& Clark, R. F. Toxicology and overdose of atypical antipsychotics. J Emerg Med. 2012;43(5):906-913.

34. Levine, M. \& Ruha, A. M. Overdose of atypical antipsychotics: clinical presentation, mechanisms of toxicity and management [published correction appears in CNS Drugs. 2012; 26(9):812]. CNS Drugs. 26, 601-611 (2012).

35. Burns, M. J. The pharmacology and toxicology of atypical antipsychotic agents. J Toxicol Clin Toxicol. 39, 1-14 (2001).

36. Agid, O. et al. Antipsychotic response in first-episode schizophrenia: efficacy of high doses and switching. Eur Neuropsychopharmacol. 23, 1017-1022 (2013).

37. Elie, D., Poirier, M., Chianetta, J., Durand, M., Grégoire, C. \& Grignon, S. Cognitive effects of antipsychotic dosage and polypharmacy: a study with the BACS in patients with schizophrenia and schizoaffective disorder. J Psychopharmacol. 24, 1037-1044 (2010).

38. Torniainen, M. et al. Antipsychotic treatment and mortality in schizophrenia [published correction appears in Schizophr Bull. 2016; 42(2):528]. Schizophr Bull. 41, 656-663 (2015).

39. Sultana, J. et al. Antipsychotic utilization patterns among patients with schizophrenic disorder: a cross-national analysis in four countries. Eur J Clin Pharmacol. 75, 1005-1015 (2019).

40. de la Iglesia-Larrad, J. I. et al. Benzodiazepine abuse, misuse, dependence, and withdrawal among schizophrenic patients: A review of the literature. Psychiatry Res. 284, 112660 (2020).

41. Upthegrove, R., Marwaha, S. \& Birchwood, M. Depression and Schizophrenia: Cause, Consequence, or Trans-diagnostic Issue? Schizophr Bull. 43, 240-244 (2017).

42. Rummel-Kluge, C. et al. Second-generation antipsychotic drugs and extrapyramidal side effects: a systematic review and meta-analysis of head-to-head comparisons. Schizophr Bull. 38, 167-177 (2012).

43. Huhn, M. et al. Comparative efficacy and tolerability of 32 oral antipsychotics for the acute treatment of adults with multi-episode schizophrenia: a systematic review and network meta-analysis [published correction appears in Lancet. 2019 Sep 14;394(10202):918]. Lancet. 394, 939-951 (2019).

44. Zun, L. S. Evidence-Based Review of Pharmacotherapy for Acute Agitation. Part 1: Onset of Efficacy. J Emerg Med. 54, 364-374 (2018).

45. Gaviria, A. M. et al. A Non-Interventional Naturalistic Study of the Prescription Patterns of Antipsychotics in Patients with Schizophrenia from the Spanish Province of Tarragona. PLoS One. 10, e0139403 (2015).

46. Bernardo, M., Coma, A., Ibáñez, C., Zara, C., Bari, J. M. \& Serrano-Blanco, A. Antipsychotic polypharmacy in a regional health service: a population-based study. BMC Psychiatry. 2012;12:42. 
47. Kane, J. M. et al. Clinical Guidance on the Identification and Management of Treatment-Resistant Schizophrenia. J Clin Psychiatry. 80, 18com12123 (2019).

48. Wimberley, T., Gasse, C., Meier, S. M., Agerbo, E., MacCabe, J. H. \& Horsdal, H.T. Polygenic Risk Score for Schizophrenia and Treatment-Resistant Schizophrenia. Schizophr Bull. 43, 1064-1069 (2017).

49. Sanz-Fuentenebro, F. J., Uriarte, J. J. U., Bonet, P., Molina, V. \& Bernardo, M. Pattern of use of clozapine in Spain. Variability and under-prescription. Patrón de uso de clozapina en España. Variabilidad e infraprescripción. Rev Psiquiatr Salud Ment. 12, 151-162 (2019).

50. Rubio, J. M. \& Kane, J. M. How and when to use clozapine. Acta Psychiatr Scand. 141, 178-189 (2020)

51. Remington, G., Addington, D., Honer, W., Ismail, Z., Raedler, T. \& Teehan, M. Guidelines for the Pharmacotherapy of Schizophrenia in Adults. Can J Psychiatry.62, 604-616 (2017)

\section{Figures}




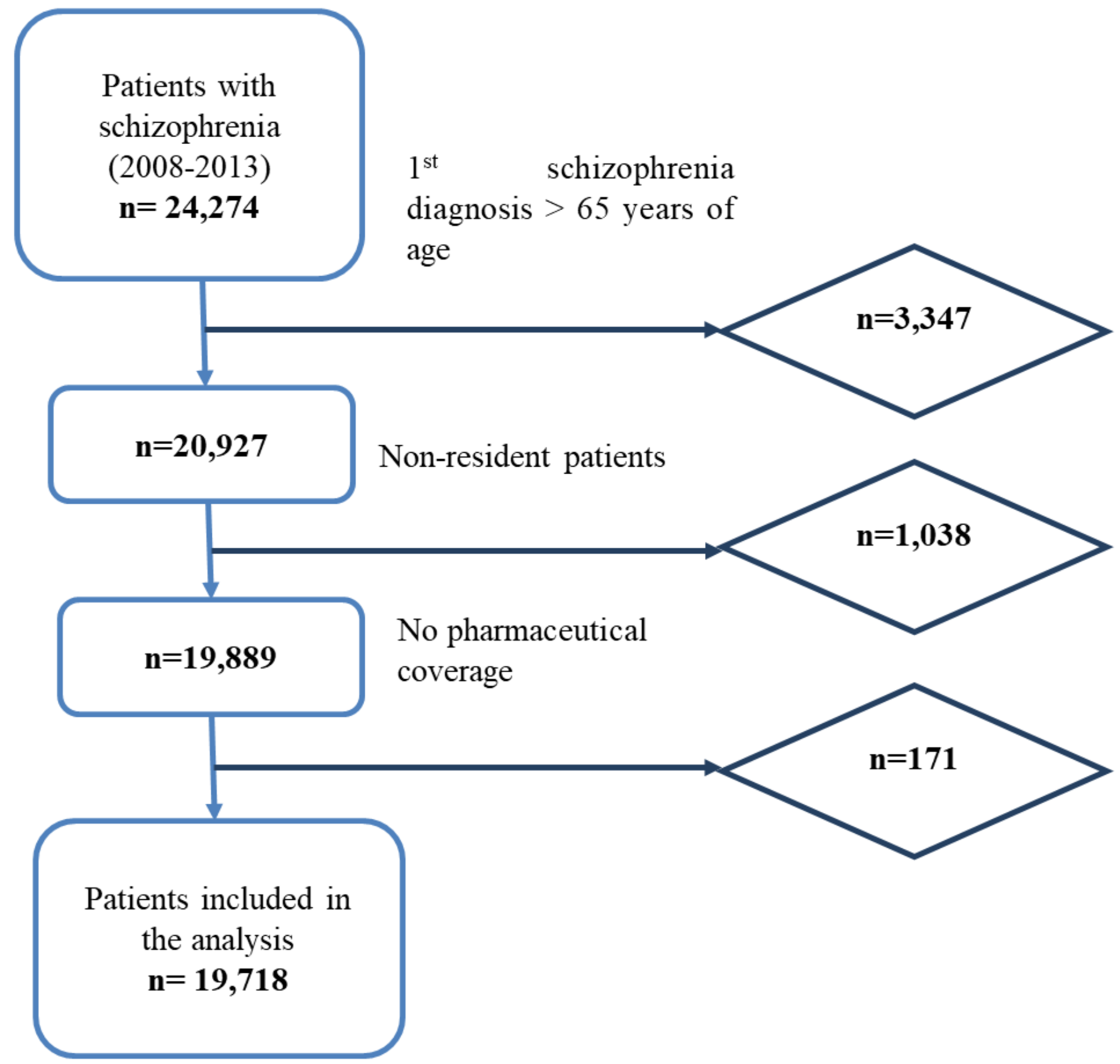

Figure 1

Study flow-chart 


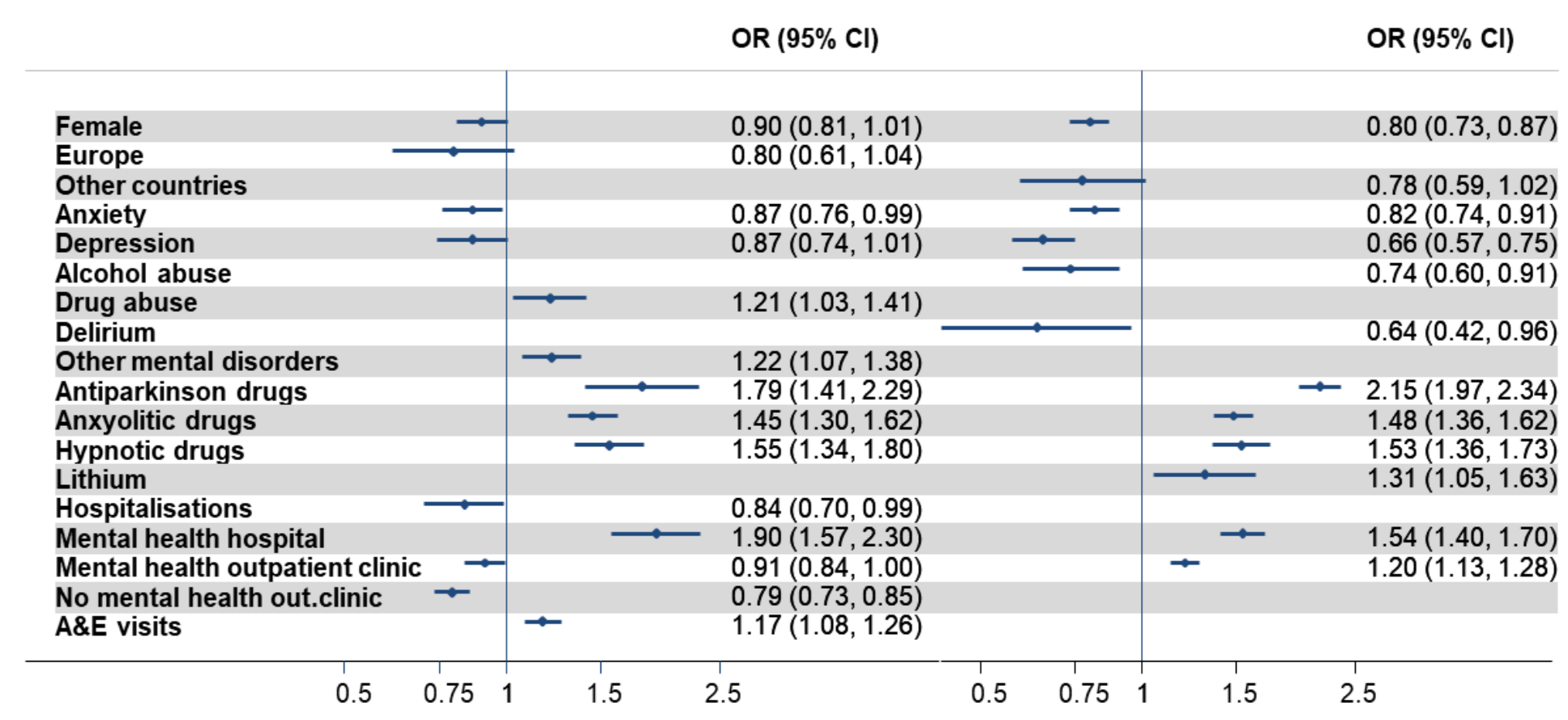

Figure 2

Factors associated with antipsychotic polypharmacy. Both logistic models included all variables in Table 1. Abbreviations: $\mathrm{OR}=$ Odds Ratio, out.=outpatient, $\mathrm{A} \& \mathrm{E}=\mathrm{Accident}$ and Emergencies, $\mathrm{Cl}=$ Confidence Interval

\section{Supplementary Files}

This is a list of supplementary files associated with this preprint. Click to download.

- SUPPLEMENTARYINFORMATION.pdf 